\title{
Hyperphosphate-Induced Myocardial Hypertrophy through the GATA-4/NFAT-3 Signaling Pathway Is Attenuated by ERK Inhibitor Treatment
}

\author{
Yao-Lung Liu a, b Chiu-Ching Huang ${ }^{a, b} \quad$ Chiz-Chung Chang a, b \\ Che-Yi Chou ${ }^{a}, b$ Shih-Yi Lin a I-Kuan Wang ${ }^{a, b}$ Dennis Jine-Yuan Hsieh ${ }^{e, f}$ \\ Gwo-Ping Jong ${ }^{f}$ Chih-Yang Huang ${ }^{c, g}$ Chao-Min Wang ${ }^{d}$ \\ ${ }^{a}$ Division of Nephrology and Kidney Institute, China Medical University Hospital, bSchool \\ of Medicine, ' Graduate Institute of Basic Medical Science, and d Research Center for \\ Biodiversity, China Medical University, e School of Medical Laboratory and Biotechnology, \\ Chung Shan Medical University, ${ }^{f}$ Department of Clinical Laboratory, Chung Shan Medical \\ University Hospital, and ${ }^{9}$ Department of Health and Nutrition Biotechnology, Asia \\ University, Taichung, Taiwan, ROC
}

\section{Key Words}

Hyperphosphate $\cdot$ Cardiomyocyte hypertrophy $\cdot$ Calcineurin $\cdot$ ERK inhibitor

\begin{abstract}
Background/Aims: Numerous epidemiological studies have associated elevated serum phosphorus levels with cardiovascular disease and the risk of death in the general population as well as in chronic kidney disease (CKD) and dialysis patients. In this study, we explored whether elevated phosphate conditions induce cardiac hypertrophy and attempted to identify the molecular and cellular mechanisms in the hypertrophic response. Methods: H9c2 myocardial cells were incubated in high-phosphate conditions to induce hypertrophy. Pathological hypertrophic responses were measured in terms of cell size, arrangement of actin filaments, and hypertrophy markers such as atrial natriuretic peptide (ANP) and B-type natriuretic peptide (BNP) in myocardial cells. Several transcriptional factors involved in cardiac hypertrophy development were measured to investigate the molecular pathways involved in elevated phosphate-induced cardiac hypertrophy. Results: High-phosphate conditions induced cellular hypertrophy, marked by increased cell size, reorganization of actin filaments, and upregulation of both ANP and BNP in $\mathrm{H} 9 \mathrm{c} 2$ cells. Both upstream calcineurin and downstream transcription factors, including GATA-4 and NFAT-3, were significantly increased under hyperphosphate conditions. Moreover, both MEK1/2 and ERK1/2 expression increased significantly, and cellular hypertrophy was markedly attenuated by U0126, an ERK1/2 inhibitor. Conclusions: These results suggest that hyperphosphate conditions induce myocardial hypertrophy through the ERK signaling pathway in H9c2 cells. Our findings provide a link be-
\end{abstract}

Chih-Yang Huang, PhD

Graduate Institute of Basic Medical Science

China Medical University, 91 Hsueh-Shih Road

Taichung 404, Taiwan (ROC)

E-Mail cyhuang @ mail.cmu.edu.tw
Chao-Min Wang, PhD

Research Center for Biodiversity, China Medical University

Room 721, 7F, Lifu Hall, 91 Hsueh-Shih Road

Taichung 404, Taiwan (ROC)

E-Mail leo8wang@yahoo.com.tw 
tween the hyperphosphate-induced response and the ERK/NFAT-3 signaling pathway that mediates the development of cardiac hypertrophy. In view of the potent and selective activity of the ERK inhibitor U0126, this agent warrants further investigation as a candidate for preventing hyperphosphate-induced cardiac hypertrophy in CKD and dialysis patients.

(C) 2015 S. Karger AG, Basel

\section{Introduction}

Phosphate levels are strongly associated with poor outcomes in patients with chronic kidney disease (CKD) and end-stage renal disease (ESRD) [1-4]. Several epidemiological studies have documented a link between serum phosphorus and adverse outcomes in CKD $[3,4]$. In addition, a high serum phosphate level is also highly correlated with the extent of vascular calcification and vascular disease [5]. Many people worldwide have combined cardiovascular disease and CKD [6]. Cardiovascular complications are the major cause of death in patients with ESRD [7]. More recent observational data have associated hyperphosphatemia with increased cardiovascular mortality among dialysis patients [8, 9]. Phosphorus levels are also associated with subclinical atherosclerosis in the general population and young adults $[10,11]$. A recent report has demonstrated that conventional hemodialysis is associated with significant left ventricular hypertrophy [12]. Abnormal mineral metabolism, especially hyperphosphatemia, is now considered a novel cardiovascular risk factor among dialysis patients. However, the reasons and mechanisms responsible for phosphorus dampening are only partially understood, because the putative receptor mediating phosphorus toxicity in target organs has not yet been identified.

Intracellular signaling pathways of the cardiac hypertrophic response are typically induced by active membrane-bound receptors including multiple GTPase proteins, kinases, and phosphatases [13]. In the heart, mitogen-activated protein kinase (MAPK) signaling pathways and the $\mathrm{Ca}^{2+} /$ calmodulin-activated protein phosphatase calcineurin have been reported to participate in the development of cardiac hypertrophy in response to stimuli [13-15]. However, no experiments have been conducted to establish a causal relationship between hyperphosphate and hypertrophy of myocardial cells. In the present study, we first examined whether hyperphosphate induces cardiac hypertrophy and subsequently identified the precise molecular and cellular mechanisms involved in the hypertrophic response induced by hyperphosphate in myocardial cells.

\section{Materials and Methods}

Elevated Phosphate-Induced Hypertrophy in Myocardial Cells

Cardiomyoblast cells (H9c2) were cultured in Dulbecco's modified Eagle's medium supplemented with 10\% fetal bovine serum (Clontech, Mountain View, Calif., USA), 2 mm glutamine, 1 mm HEPES buffer, and antibiotics $\left(100 \mu \mathrm{g} / \mathrm{ml}\right.$ penicillin, $100 \mu \mathrm{g} / \mathrm{ml}$ streptomycin) in $5 \% \mathrm{CO}_{2}$ at $37^{\circ} \mathrm{C}$. For treatment with elevated phosphate, the $\mathrm{H} 9 \mathrm{c} 2$ cells were incubated in different concentrations of $\mathrm{NaH}_{2} \mathrm{PO}_{4}$. Cell sizes were calculated at various time intervals. Finally, the best condition was used to induce cellular hypertrophy in myocardial cells.

Cell Size Measurement

The cell surface area was determined after imaging by fluorescence microscopy. H9c2 cells were fixed with $4 \%$ paraformaldehyde, washed with ice-cold PBS, permeabilized with $0.5 \%$ Triton X-100, and blocked with PBS containing 2\% bovine serum albumin as described previously [16]. Actin filaments were stained using rhodamine-labeled phalloidin (Molecular Probes, USA). Surface areas were quantified by visualizing the boundary of individual cells by using Zeiss AxioVision software. For each treatment condition, 30 cells were counted in triplicate. 


\section{CardioRenal Medicine}

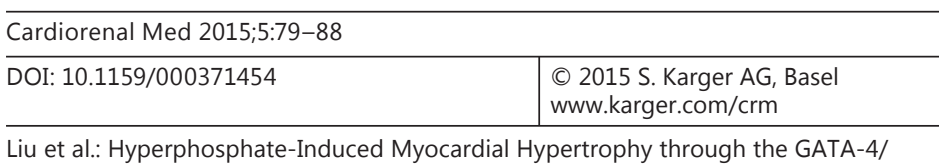

Liu et al.: Hyperphosphate-Induced Myocardial Hypertrophy through the GATA-4/ NFAT-3 Signaling Pathway Is Attenuated by ERK Inhibitor Treatment

\section{Immunoblotting}

Crude proteins of cultured myocardial cells were isolated using lysis buffer (Roche Molecular Biochemicals, Indianapolis, Ind., USA). Nuclear protein was extracted as per a protocol reported previously [16]. The protein concentration in the supernatant was determined by the colorimetric assay (Bio-Rad, Hercules, Calif., USA). Samples containing $50 \mu \mathrm{g}$ of protein were analyzed by Western blot. Antibodies against atrial natriuretic peptide (ANP), B-type natriuretic peptide (BNP), GATA-4, phosphorylated GATA-4, and NFAT-3, as well as goat anti-mouse IgG antibody conjugated to horseradish peroxidase, goat anti-rabbit IgG antibody conjugated to horseradish peroxidase, and goat anti-rabbit IgG horseradish peroxidase conjugate were obtained from Santa Cruz Biotechnology Inc. (Santa Cruz, Calif., USA). We used $\alpha$-tubulin (Lab Vision Corporation, Fremont, Calif., USA) as the loading control.

Inhibitor Treatments

p38 MAPK inhibitor (SB203580), JNK inhibitor (SP600125), ERK1/2 inhibitor (U0126), and calcineurin inhibitor [cyclosporine A (CsA)] were obtained from Tocris (Ellisville, Mo., USA). H9c2 cells were preincubated with U0126 (1 $\mu \mathrm{M}), \mathrm{SB} 203580(1 \mu \mathrm{M})$, SP600125 $(1 \mu \mathrm{M})$, and CsA $(1 \mu \mathrm{M})$ for $1 \mathrm{~h}$, followed by $\mathrm{NaH}_{2} \mathrm{PO}_{4}$ for $6 \mathrm{~h}$. Actin immunofluorescence was performed to determine the effect of these inhibitors on the cardiomyocyte hypertrophy induced by elevated phosphate conditions.

\section{Statistical Analysis}

All statistical analyses were conducted using SPSS 13.0 software. Each experiment was replicated at least 3 times. The results are presented as the average mean \pm standard error (SE), and statistical comparisons were made using Student's $t$ test. A p value $<0.05$ was considered statistically significant.

\section{Results}

Hyperphosphate Conditions Induce Cellular Hypertrophy and Upregulate the Pathologic Hypertrophy Markers ANP and BNP in Myocardial Cells

Myocardial cells showing hypertrophy induced by elevated levels of phosphate were analyzed by performing immunofluorescence to examine actin fibers and cell sizes. The results showed that the surface area of $\mathrm{H} 9 \mathrm{c} 2$ cells increased significantly, approximately 1.3-, 1.8-, 1.5-, and 1.2-fold in response to $1.2,1.4,1.6$, and $1.8 \mathrm{~mm} \mathrm{NaH}_{2} \mathrm{PO}_{4}$ treatment, respectively, as compared to the control. In addition, the $\mathrm{H} 9 \mathrm{c} 2$ cell surface area increased significantly at different time intervals under $1.4 \mathrm{mM} \mathrm{NaH}_{2} \mathrm{PO}_{4}$ treatment conditions (fig. 1).

Cell lysates were analyzed for the pathologic hypertrophy markers ANP and BNP. As shown in figure 2, $\mathrm{H} 9 \mathrm{c} 2$ cell cultures were treated with $1.4 \mathrm{mM} \mathrm{NaH}_{2} \mathrm{PO}_{4}$ for $24 \mathrm{~h}$ and analyzed by Western blot using antibodies against ANP and BNP. ANP significantly increased within $1 \mathrm{~h}$ following treatment, and the levels were maintained for up to $24 \mathrm{~h}$. BNP levels increased $6 \mathrm{~h}$ after treatment and reached a maximum at $24 \mathrm{~h}$.

Elevated Phosphate Conditions Induce an Increase in Calcineurin Expression, GATA-4 Activation, and NFAT-3 Nuclear Localization in Myocardial Cells

As shown in figure 3, elevated phosphate conditions induced an increase in calcineurin expression within $6 \mathrm{~h}$ and phosphorylation/activation of GATA-4 within $3 \mathrm{~h}$, and the active state of GATA-4 was maintained for up to $24 \mathrm{~h}$. NFAT-3 levels increased in a time-dependent manner during the first $12 \mathrm{~h}$. These results suggest that elevated phosphate conditions induce the development of myocardial hypertrophy through calcineurin and the activation of GATA-4 and nuclear localization of NFAT-3.

MAPKs Mediate Elevated Phosphate-Induced Myocardial Hypertrophy

To further elucidate the signal transduction pathway involved in the mechanism of elevated phosphate-induced myocardial hypertrophy, MAPKs such as ERK, MEK, JNK, and 


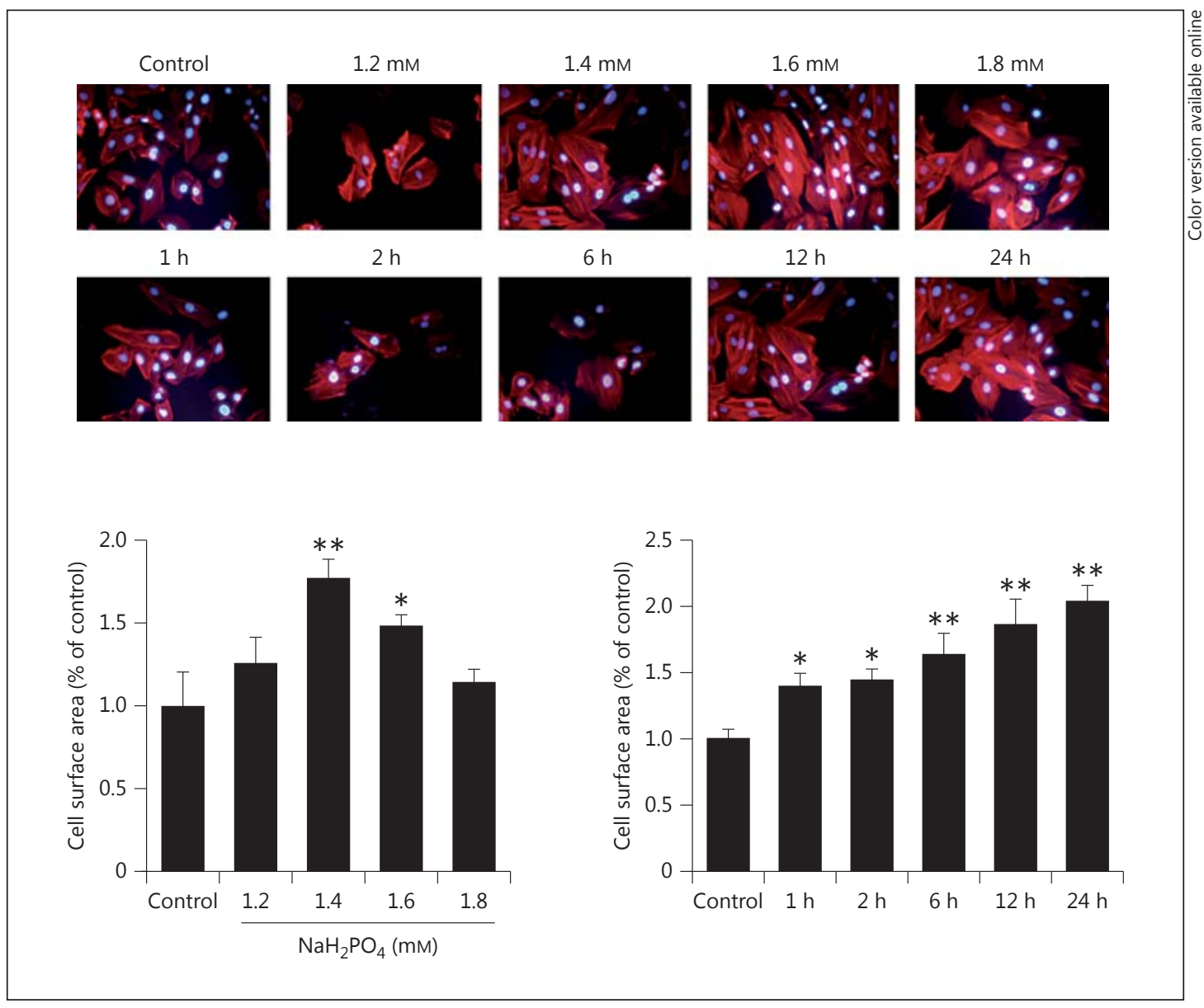

Fig. 1. Cell size measurements in elevated phosphate-induced hypertrophic myocardial cells, performed using actin immunofluorescence staining. $\mathrm{H} 9 \mathrm{c} 2$ myocardial cells were cultured with different concentrations of $\mathrm{NaH}_{2} \mathrm{PO}_{4}$ and treated with $1.4 \mathrm{mM} \mathrm{NaH}_{2} \mathrm{PO}_{4}$ for various time periods $(1,2,6,12$, and $24 \mathrm{~h})$. The cell surface area was observed using fluorescence microscopy. The results are expressed as the mean \pm SE values of 3 experiments. $* \mathrm{p}<0.05,{ }^{* *} \mathrm{p}<0.01$ in comparison to the control.

p38 were analyzed by Western blot. Elevated phosphate-induced myocardial hypertrophy increased the expression of ERK only at $6 \mathrm{~h}$ after treatment. In addition, the level of MEK expression increased within $1 \mathrm{~h}$ and decreased after $6 \mathrm{~h}$ as compared to the control (fig. 4). These results show that the MAPK pathway is involved in elevated phosphate-induced myocardial hypertrophy.

\section{Potential Inhibitors of Elevated Phosphate-Induced Myocardial Hypertrophy}

To confirm the involvement of the MAPK signal transduction pathway and identify potential inhibitors of elevated phosphate-induced myocardial hypertrophy, the signal transduction inhibitors CsA (calcineurin inhibitor), U0126 (ERK1/2 inhibitor), SB203580 (p38 MAPK inhibitor), and SP600125 (JNK1/2 inhibitor) were used to block MAPK and calcineurin-mediated pathways in H9c2 cells. The results showed that the ERK1/2 inhibitor U0126 suppressed elevated phosphate-induced cell size hypertrophy significantly (fig. 5). CsA and the other MAPK inhibitors, namely SB203580 and SP600125, had no effect on cell size in phosphate-induced hypertrophy (fig. 5). These results indicate that the $\mathrm{Ca}^{2+} / \mathrm{calmod}^{2}$ 


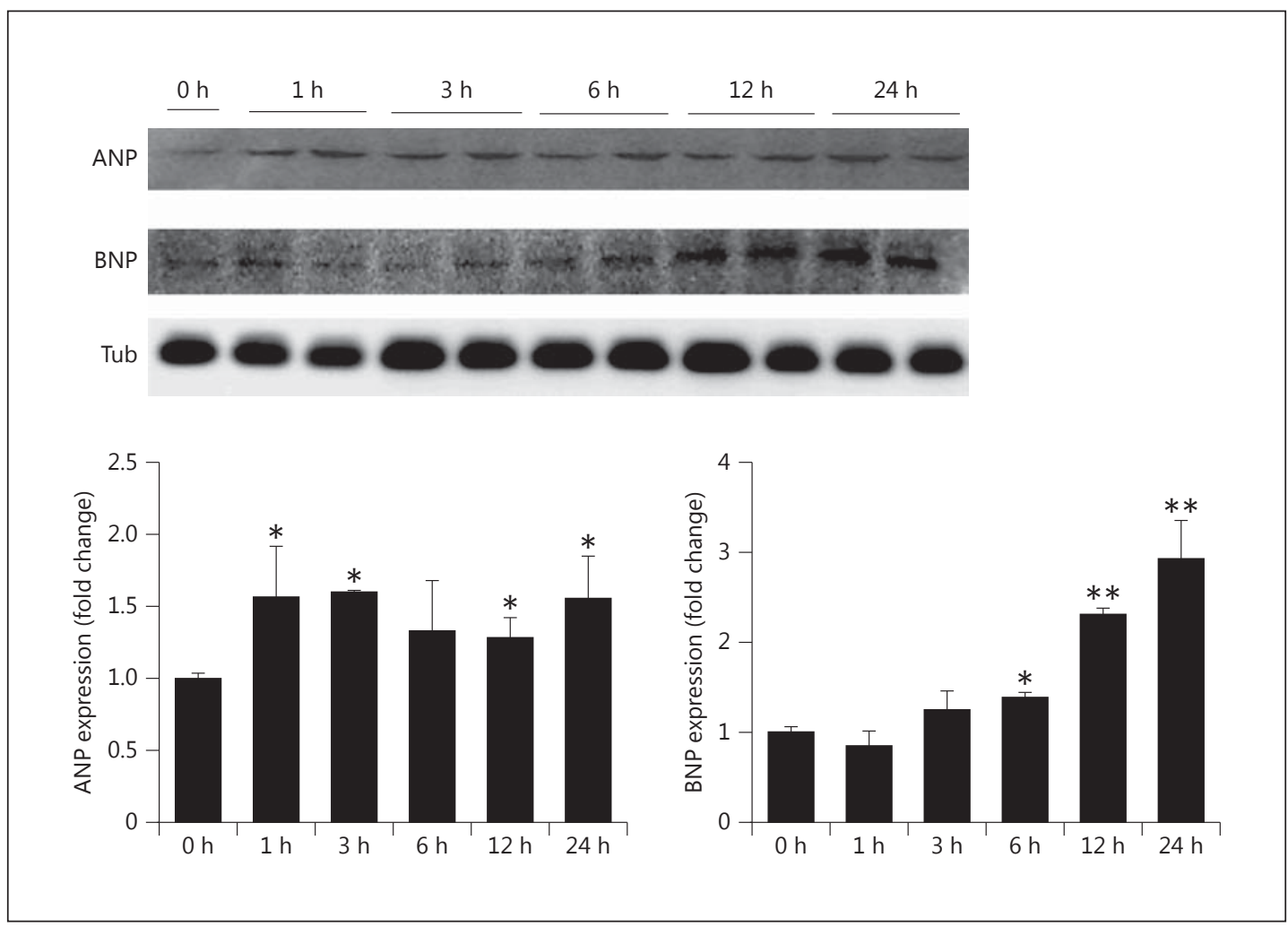

Fig. 2. Expression of pathologic markers (ANP and BNP) in elevated phosphate-induced myocardial cells. The expression levels of ANP and BNP with $1.4 \mathrm{mM} \mathrm{NaH}_{2} \mathrm{PO}_{4}$ were measured by immunoblotting with antibodies against proteins as indicated. The results are expressed as the mean \pm SE values of 3 experiments. ${ }^{*} \mathrm{p}<0.05,{ }^{* *} \mathrm{p}<0.01$ in comparison to the control. Tub $=\alpha$-Tubulin.

ulin-activated protein phosphatase calcineurin is not involved in the regulation of elevated phosphate-induced hypertrophy. They confirm that ERK1/2 play an important role in elevated phosphate-induced myocardial hypertrophic response.

\section{Discussion}

High serum phosphate is a major risk factor for cardiovascular disease and vascular calcification. Numerous epidemiological studies have associated serum phosphorus levels with different markers of cardiovascular disease $[2,5,10,11]$ and the risk of death in the general population [6, 17] as well as in CKD and dialysis patients $[1,3,4]$. Therefore, establishing a causal relationship between elevated serum phosphate levels and hypertrophy of myocardial cells is essential. In this study, we first explored the molecular and cellular mechanisms behind the hypertrophic response induced by elevated phosphate conditions in myocardial cells. We demonstrated that elevated phosphate conditions induce a hypertrophic response in H9c2 cells, marked by an increased cell surface area, a reorganization of actin filaments, and an upregulation of hypertrophy markers (ANP and BNP). Both transcription factors GATA-4 and NFAT-3 are important for the development of cardiac hypertrophy. Finally, our results demonstrated that the characteristic features of cardiac hypertrophy in H9c2 cells are mediated by the ERK1/2 signaling pathway (fig. 6). 


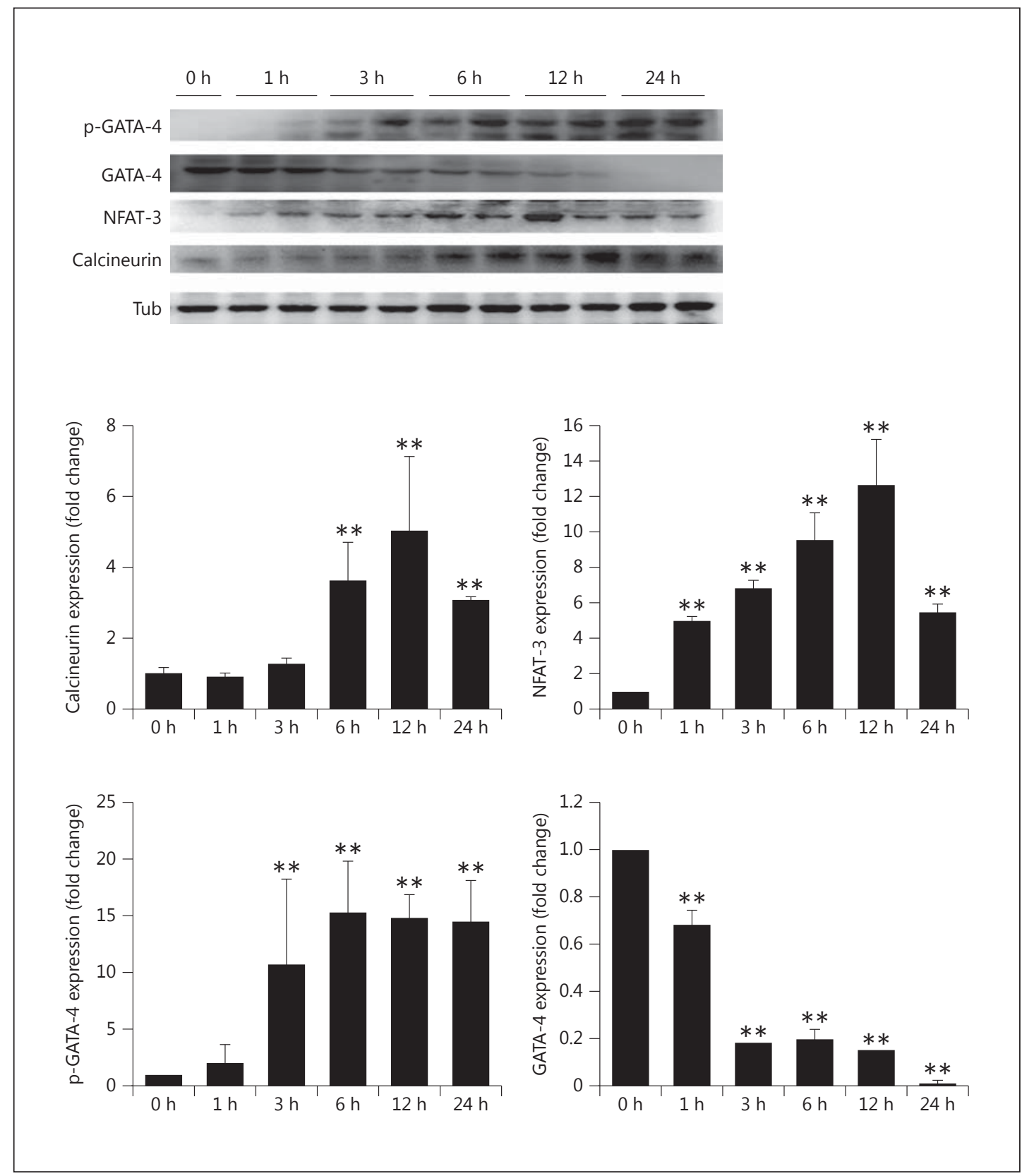

Fig. 3. Expression of calcineurin and GATA-4 and nuclear localization of NFAT-3 in elevated phosphate-induced myocardial cells with $1.4 \mathrm{mM} \mathrm{NaH}_{2} \mathrm{PO}_{4}$. The protein levels of calcineurin, GATA-4, and phosphorylated (p-)GATA-4 and the nuclear fraction of NFAT-3 were determined by Western blot analysis. The results are expressed as the mean \pm SE values of 3 experiments. ${ }^{* *} p<0.01$ in comparison to the control. Tub $=\alpha$-Tubulin.

The MAPK pathway is important in transferring external stimuli to the nucleus via the phosphorylation and regulation of several transcription factors. Serine-threonine kinases have been shown to phosphorylate important downstream mediators that participate in the regulation of cellular functions such as proliferation, differentiation, apoptosis, and growth processes including cardiac hypertrophy [18]. MAPKs can be divided into three subfamilies on the basis of sequence homology, namely ERKs, JNKs, and p38. Growing evidence shows 


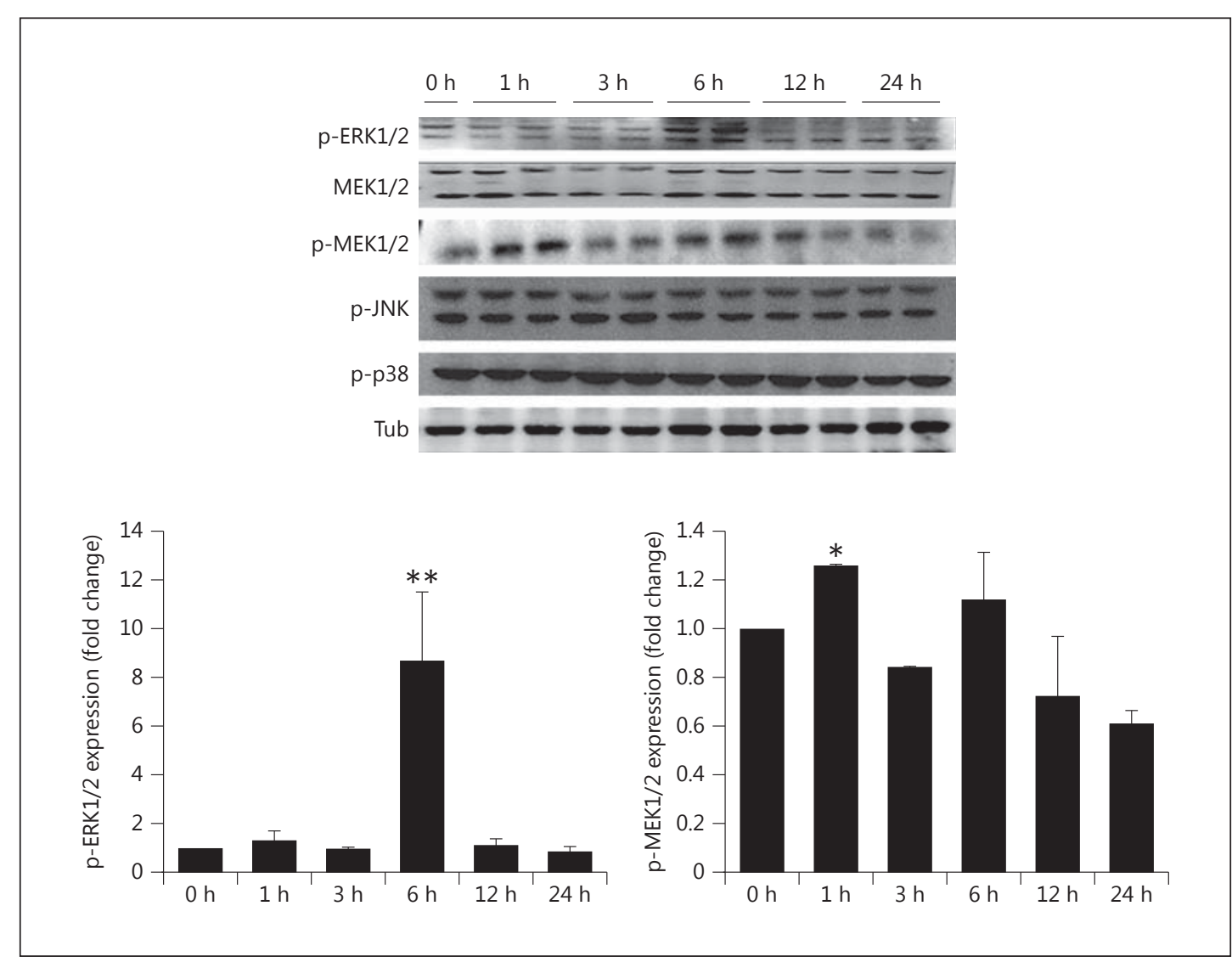

Fig. 4. Expression of MAPK markers in elevated phosphate-induced myocardial cells with $1.4 \mathrm{mM} \mathrm{NaH}_{2} \mathrm{PO}_{4}$. The protein levels of MEK1/2, phosphorylated (p-)ERK1/2, p-MEK1/2, p-JNK, and p-p38 were determined by Western blot analysis. The results are expressed as the mean \pm SE values of 3 experiments. $* p<0.05$, ** $\mathrm{p}<0.01$ in comparison to the control. Tub $=\alpha$-Tubulin.

that environmental stress (osmotic stress, DNA damage, and ultraviolet radiation) stimulates cardiomyocyte hypertrophy and activates protein kinase cascades including ERK, p38 MAPK, and JNK [19]. Interestingly, the significant role for these pathways in hypertrophic signaling was confirmed by overexpression of MAPK phosphatase 1, which inhibits all three major factors of MAPK signaling and blocks cardiac hypertrophy both in vitro and in vivo [20]. In this study, pretreatment with ERK, but not with JNK or the p38 MAPK inhibitor, showed suppressive effects on hypertrophic changes such as the reorganization of actin filaments. These results indicate that hypertrophy is specifically suppressed by an ERK inhibitor.

A previous study has demonstrated that the calcineurin/NFAT signaling pathway plays an important role in the development of cardiac hypertrophy [21]. It was also shown that calcineurin activity is increased in compensated hypertrophic human myocardium and endstage heart failure [22]. However, pretreatment with the calcineurin inhibitor CsA showed slight effects on hypertrophic features such as the reorganization of actin filaments in this study. These results suggest that the $\mathrm{Ca}^{2+} /$ calmodulin-activated protein phosphatase calcineurin is not involved in elevated phosphate-induced hypertrophic responses of $\mathrm{H} 9 \mathrm{c} 2$ myocardial cells.

Another previous study has indicated that poor outcomes in patients with CKD and ESRD were associated with serum phosphate levels [23]. Additionally, observational studies have 


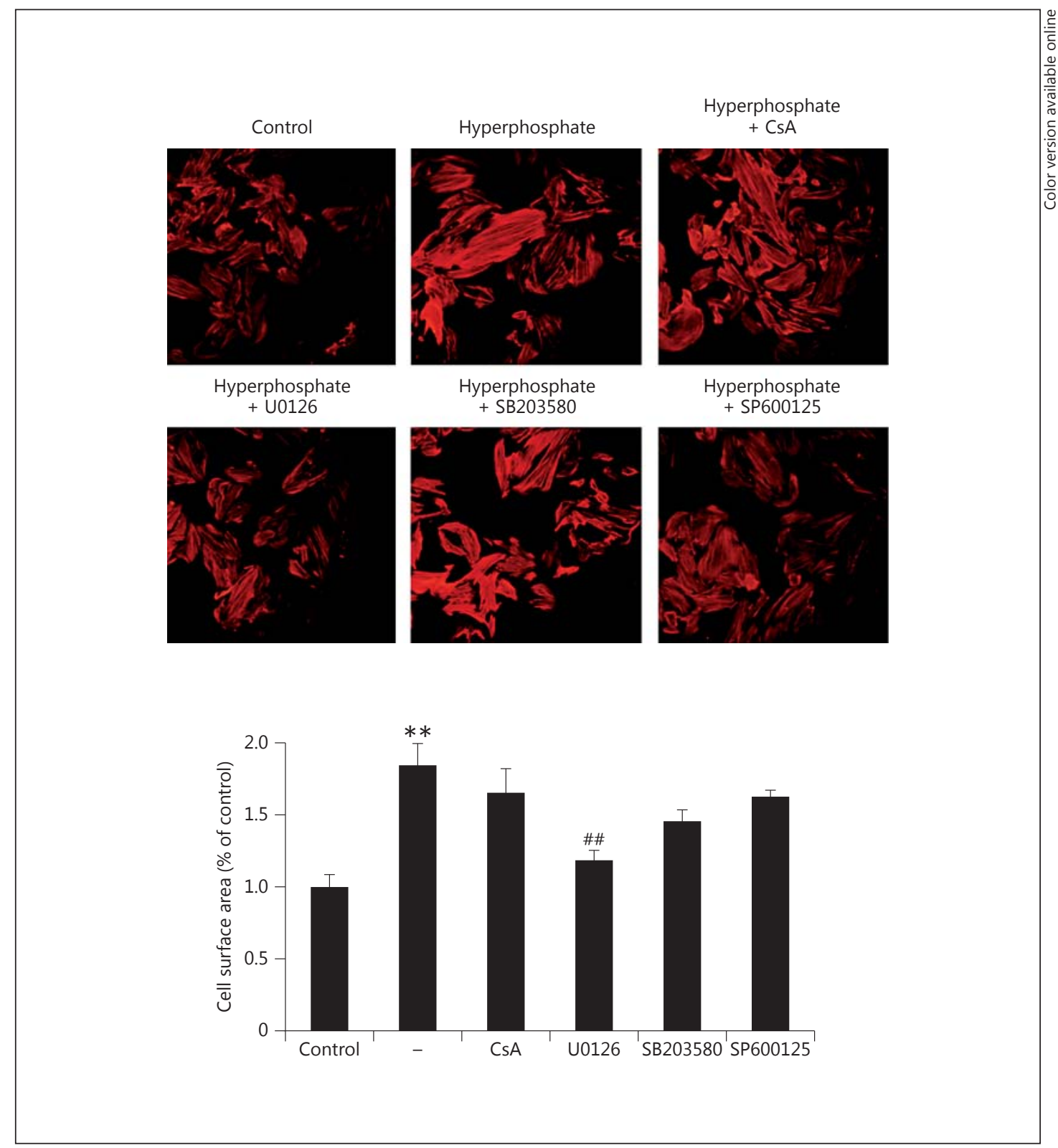

Fig. 5. Potential inhibitors of elevated phosphate-induced myocardial hypertrophy. H9c2 myocardial cells were pretreated with potential inhibitors, namely CsA (calcineurin inhibitor), U0126 (ERK1/2 inhibitor), SB203580 (p38 MAPK inhibitor), and SP600125 (JNK1/2 inhibitor), for $1 \mathrm{~h}$ and subsequently underwent elevated phosphate treatment (1.4 mM) for $6 \mathrm{~h}$. Cells cultured without pretreatment were used as a control. The effect of various inhibitors on elevated phosphate-induced myocardial hypertrophy was determined by the actin immunofluorescence assay. The relative cell size in response to different inhibitors was analyzed, where 30 cells were counted in each experiment, performed in triplicate. The results are expressed as the mean \pm SE values of 3 experiments. ${ }^{* *} \mathrm{p}<0.01$ in comparison to the control; ${ }^{\# \#} \mathrm{p}<0.01$ in comparison to phosphate treatment. 


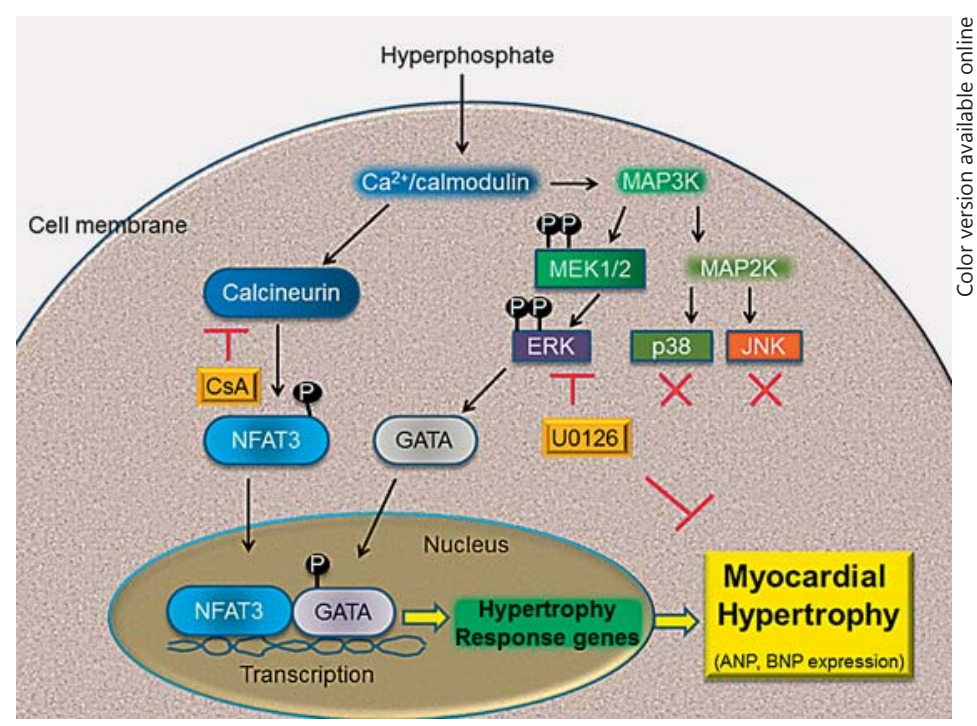

Fig. 6. Signaling pathway involved in phosphate-induced myocardial hypertrophy. Phosphate-induced myocardial hypertrophy critically prompts the activation of calcineurin. Calcineurin dephosphorylates the NFAT3 transcription factor in the cytoplasm, and the dephosphorylated NFAT-3 further interacts with the GATA-4 transcription factor in the nucleus to turn on the expression of hypertrophy response genes such as ANP and BNP that participate in the development of myocardial hypertrophy. Administration of the pharmacological agent CsA may completely block calcineurin enzymatic activity but may have no significant inhibitory effect on myocardial hypertrophy. Moreover, MEK1/2-ERK1/2 expression both increase significantly, and cellular hypertrophy is markedly attenuated by U0126, an ERK1/2 inhibitor. These results suggest that hyperphosphate induces myocardial hypertrophy through the ERK signaling pathway in H9c2 cells.

correlated the use of phosphate binders as a tool for controlling hyperphosphatemia with better survival rates in CKD and ESRD [7, 24]. However, the use of phosphate binders in CKD is based on observational rather than clinical trial data, and these suggest only a limited effect of phosphate binders [24]. This study revealed that elevated phosphate levels induce myocardial hypertrophy in H9c2 cells via the ERK signaling pathway. To prevent cardiac hypertrophy in CKD and dialysis patients, we propose that blocking the ERK/NFAT-3 signaling pathway - using a pharmacological ERK inhibitor such as U0126 - may be a good therapeutic approach, thus preventing pathological hypertrophy and heart dysfunction. Considering the growing incidence of dialysis and CKD, we believe that this area should be prioritized for future research. Further studies are required to explore candidate ERK inhibitors for clinical applications.

\section{Acknowledgements}

This study was financially supported by grants from the China Medical University Hospital to Y.-L.L., and in part by the Taiwan Ministry of Health and the Welfare Clinical Trial and Research Center of Excellence (DOH102-TD-B-111-004).

\section{Disclosure Statement}

No competing interests exist. 


\section{References}

1 Eddington H, Hoefield R, Sinha S, Chrysochou C, Lane B, Foley RN, Hegarty J, New J, O’Donoghue DJ, Middleton RJ, Kalra PA: Serum phosphate and mortality in patients with chronic kidney disease. Clin J Am Soc Nephrol 2010;5:2251-2257.

-2 Ix JH, De Boer IH, Peralta CA, Adeney KL, Duprez DA, Jenny NS, Siscovick DS, Kestenbaum BR: Serum phosphorus concentrations and arterial stiffness among individuals with normal kidney function to moderate kidney disease in MESA. Clin J Am Soc Nephrol 2009;4:609-615.

-3 Kestenbaum B, Sampson JN, Rudser KD, Patterson DJ, Seliger SL, Young B, Sherrard DJ, Andress DL: Serum phosphate levels and mortality risk among people with chronic kidney disease. J Am Soc Nephrol 2005;16: 520-528.

-4 Menon V, Greene T, Pereira AA, Wang X, Beck GJ, Kusek JW, Collins AJ, Levey AS, Sarnak MJ: Relationship of phosphorus and calcium-phosphorus product with mortality in CKD. Am J Kidney Dis 2005;46:455-463.

5 London GM, Guerin AP, Marchais SJ, Metivier F, Pannier B, Adda H: Arterial media calcification in end-stage renal disease: impact on all-cause and cardiovascular mortality. Nephrol Dial Transplant 2003;18:17311740.

-6 Dhingra R, Sullivan LM, Fox CS, Wang TJ, D’Agostino RB, Gaziano JM, Vasan RS: Relations of serum phosphorus and calcium levels to the incidence of cardiovascular disease in the community. Arch Intern Med 2007;167: 879-885.

7 Coladonato JA: Control of hyperphosphatemia among patients with ESRD. J Am Soc Nephrol 2005;16:S107S114.

-8 Voormolen N, Noordzij M, Grootendorst DC, Beetz I, Sijpkens YW, van Manen JG, Boeschoten EW, Huisman RM, Krediet RT, Dekker FW; PREPARE Study Group: High plasma phosphate as a risk factor for decline in renal function and mortality in pre-dialysis patients. Nephrol Dial Transplant 2007;22:2909-2916.

-9 Block GA, Hulbert-Shearon TE, Levin NW, Port FK: Association of serum phosphorus and calcium $\times$ phosphate product with mortality risk in chronic hemodialysis patients: a national study. Am J Kidney Dis 1998;31:607617.

10 Onufrak SJ, Bellasi A, Shaw LJ, Herzog CA, Cardarelli F, Wilson PW, Vaccarino V, Raggi P: Phosphorus levels are associated with subclinical atherosclerosis in the general population. Atherosclerosis 2008;199:424-431.

-11 Foley RN, Collins AJ, Herzog CA, Ishani A, Kalra PA: Serum phosphorus levels associate with coronary atherosclerosis in young adults. J Am Soc Nephrol 2009;20:397-404.

$\$ 12$ Achinger SG, Ayus JC: Left ventricular hypertrophy: is hyperphosphatemia among dialysis patients a risk factor? J Am Soc Nephrol 2006;17:S255-S261.

13 Frey N, Olson EN: Cardiac hypertrophy: the good, the bad and the ugly. Annu Rev Physiol 2003;65:45-79.

-14 Molkentin JD, Lu JR, Antos CL, Markham B, Richardson J, Robbins J, Grant SR, Olson EN: A calcineurin-dependent transcriptional pathway for cardiac hypertrophy. Cell 1998;93:215-228.

15 Abe J, Baines CP, Berk BC: Role of mitogen-activated protein kinases in ischemia and reperfusion injury - the good and the bad. Circ Res 2000;86:607-609.

16 Liu CJ, Cheng YC, Lee KW, Hsu HH, Chu CH, Tsai FJ, Tsai CH, Chu CY, Liu JY, Kuo WW, Huang CY: Lipopolysaccharide induces cellular hypertrophy through calcineurin/NFAT-3 signaling pathway in H9c2 myocardiac cells. Mol Cell Biochem 2008;313:167-178.

17 Onufrak SJ, Bellasi A, Cardarelli F, Vaccarino V, Muntner P, Shaw LJ, Raggi P: Investigation of gender heterogeneity in the associations of serum phosphorus with incident coronary artery disease and all-cause mortality. Am J Epidemiol 2009;169:67-77.

18 Liang QR, Molkentin JD: Redefining the roles of p38 and JNK signaling in cardiac hypertrophy: dichotomy between cultured myocytes and animal models. J Mol Cell Cardiol 2003;35:1385-1394.

19 Nguyen LK, Kolch W, Kholodenko BN: When ubiquitination meets phosphorylation: a systems biology perspective of EGFR/MAPK signalling. Cell Commun Signal 2013;11:52-66.

20 Bueno OF, De Windt LJ, Lim HW, Tymitz KM, Witt SA, Kimball TR, Molkentin JD: The dual-specificity phosphatase MKP-1 limits the cardiac hypertrophic response in vitro and in vivo. Circ Res 2001;88:88-96.

21 Okamura H, Aramburu J, Garcia-Rodriguez C, Viola JPB, Raghavan A, Tahiliani M, Zhan XL, Qin J, Hogan PG, Rao A: Concerted dephosphorylation of the transcription factor NFAT1 induces a conformational switch that regulates transcriptional activity. Mol Cell 2000;6:539-550.

-22 Diedrichs H, Chi M, Boelck B, Mehlhorm U, Schwinger RHG: Increased regulatory activity of the calcineurin/ NFAT pathway in human heart failure. Eur J Heart Fail 2004;6:3-9.

23 Bellasi A, Mandreoli M, Baldrati L, Corradini M, Di Nicolo P, Malmusi G, Santoro A, Grp PN: Chronic kidney disease progression and outcome according to serum phosphorus in mild-to-moderate kidney dysfunction. Clin J Am Soc Nephrol 2011;6:883-891.

24 Block GA, Wheeler DC, Persky MS, Kestenbaum B, Ketteler M, Spiegel DM, Allison MA, Asplin J, Smits G, Hoofnagle AN, Kooienga L, Thadhani R, Mannstadt M, Wolf M, Chertow GM: Effects of phosphate binders in moderate CKD. J Am Soc Nephrol 2012;23:1407-1415. 